\title{
DHCR7 nonsense mutations and characterisation of mRNA nonsense mediated decay in Smith-Lemli-Opitz syndrome
}

\author{
L S Correa-Cerro, C A Wassif, J S Waye, P A Krakowiak*, D Cozma, N R Dobson, S W Levin, \\ G Anadiotis, R D Steiner, M Krajewska-Walasek, M J M Nowaczyk, F D Porter
}

J Med Genet 2005;42:350-357. doi: 10.1136/jimg.2004.022749

S mith-Lemli-Opitz syndrome (SLOS) is the prototypical example of a multiple congenital anomaly mental retardation syndrome due to an inborn error of cholesterol biosynthesis. The SLOS clinical spectrum ranges from a very mild disorder that combines learning and behavioural problems with minor malformations to a severe multiple malformation syndrome that results in prenatal/neonatal death. ${ }^{12}$ In 1998, three groups independently identified mutations of DHCR7 in SLOS patients. ${ }^{3-5}$ DHCR7 was mapped to chromosome 11q12-13 and encodes an NADPH dependent reductase that reduces 7 -dehydrocholesterol (7DHC) to cholesterol in the last step of cholesterol biosynthesis. Molecular studies have shown that the carrier frequency for the most common SLOS mutant allele, IVS8- $1 \mathrm{G} \rightarrow \mathrm{C}$, is approximately $1 \%$ in Caucasian populations. ${ }^{67}$ Due to the deficiency of DHCR7 activity, SLOS patients have elevated 7DHC and typically decreased cholesterol levels. Decreased cholesterol levels have been associated with birth defects due to impaired hedgehog signalling during development. ${ }^{8}$

One third of mutations underlying human disorders result in premature termination codons (nonsense mutations), which often lead to rapid degradation of the mutant mRNA by the nonsense mediated decay (NMD) pathway. ${ }^{9}$ Although the molecular mechanisms underlying NMD are not fully understood, NMD can be suppressed by experimental manipulations that impair the efficiency of translation. Aminoglycoside antibiotics, which bind to ribosomes, can induce translational read through of nonsense codons and thus suppress NMD. Restoration of protein function by NMD suppression has been reported in a number of autosomal recessive disorders such as cystic fibrosis ${ }^{10-12}$ and Hurler syndrome. ${ }^{13} 14$

Four nonsense mutations have previously been described in SLOS. These are E37X, ${ }^{15} \mathrm{Q} 149 \mathrm{X},{ }^{16} \mathrm{~W}^{151 X},{ }^{3}$ and Y217X. ${ }^{16}$ W151X represents about $6.4 \%$ of identified mutations in SLOS patients ${ }^{17}$ and by haplotype analysis appears to be a relatively old DHCR7 mutation that initially arose in Southern Poland. ${ }^{18}$ We now report a novel premature stop mutation, Q98X, and demonstrate that both Q98X and W151X undergo NMD. Because the W151X allele is relatively common, we investigated whether suppression of NMD has therapeutic potential. Although NMD can be suppressed for the W15IX allele, we found no increased fractional cholesterol synthesis in response to aminoglycoside treatment. Under identical conditions, we did observe an increase in fractional cholesterol synthesis for the Q98X cell line. This suggests that NMD suppression is unlikely to be a therapeutic option in SLOS patients with the W151X allele, but may have utility in patients with other nonsense mutations such as Q98X.

\section{METHODS}

\section{Patient population and phenotypic analysis}

This work was approved by the NICHD Institutional Review Board, and informed consent from guardians was obtained

\section{Key points}

- A novel DHCR7 nonsense mutation, Q98X, was identified.

- The phenotypic characteristics of 10 patients with the more common nonsense allele, W151X, are presented. Null mutations such as W151X allow genotype-phenotype correlations to be made for the second allele. Genotype-phenotype correlations are reviewed for common DHCR7 mutations.

- mRNA nonsense mediated decay of both the Q98X and W151X alleles is demonstrated, and the therapeutic potential of suppression of nonsense mediated decay for both of these alleles was investigated.

- Suppression of nonsense mediated decay using G418 increased fractional cholesterol synthesis in the Q98X cell line. However, G418 suppression of nonsense mediated decay of the W151X allele did not increase fractional cholesterol synthesis. This result suggests that the W151X position encodes a critical residue that cannot be substituted.

for skin biopsies or DNA analysis. Medical records and autopsy results were obtained with guardian consent. Cholesterol and 7DHC concentrations in plasma were determined by gas chromatography/mass spectrometry as previously described. ${ }^{19}$ Severity scores were calculated as previously described. ${ }^{1}$

\section{Mutation analysis}

Depending on the available sample, different methods were used to obtain genomic DNA. In cases where patient material was not available, DHCR7 genotyping was performed on DNA obtained from parents. Genomic DNA was isolated from whole blood (EDTA), using a Gentra Systems (Minneapolis, MN, USA) DNA isolation kit. Genomic DNA was purified from newborn metabolic screening blood spots ${ }^{20}$ and skin fibroblasts ${ }^{4}$ as previously described. Common SLOS mutations (IVS8-1G $\rightarrow$ C, W151X, T93M, R404C, and V326L) were excluded as previously described..$^{21}$ Coding regions were amplified from genomic DNA as previously described. ${ }^{3}$

RNA was extracted using a Qiagen RNeasy Mini Kit (Qiagen, Valencia, CA, USA). To obtain DHCR7 cDNA, RTPCR was performed using an Invitrogen Superscript OneStep RT-PCR with Platinum Taq kit (Invitrogen, Carlsbad, CA, USA). For RT-PCR the forward and reverse primers were

Abbreviations: 7DHC, 7-dehydrocholesterol; DMEM, Dulbecco's Modified Eagle's Medium; LPDS, lipoprotein deficient serum; NMD, nonsense mediated decay; SLOS, Smith-Lemli-Opitz syndrome 
HSPID (5'-AGGTGTGCGCAGGACTTTAG-3') and HSPI3 (5' GCTGGGCTCTCTCCAGTTTA-3'), respectively. Reverse transcription was performed at $50^{\circ} \mathrm{C}$ for $30 \mathrm{~min}$ followed by a 2 min denaturation at $94^{\circ} \mathrm{C}$. PCR amplification conditions were 35 cycles of $94^{\circ} \mathrm{C}$ for $15 \mathrm{~s}, 60^{\circ} \mathrm{C}$ for $30 \mathrm{~s}$, and $72^{\circ} \mathrm{C}$ for $90 \mathrm{~s}$. The reaction was completed with a final extension period of $72^{\circ} \mathrm{C}$ for $10 \mathrm{~min}$.

Sequencing primers were as previously described ${ }^{21}$ and DNA sequencing was performed on a CEQ2000 (Beckman Coulter, Fullerton, CA, USA) per the manufacturer's protocol.

\section{Cell culture}

Skin fibroblasts were cultured in Dulbecco's Modified Eagle's Medium (DMEM; Gibco-BRL, Carlsbad, CA, USA) supplemented with $10 \%$ fetal bovine serum (Gemini, Woodland, CA, USA), $100 \mathrm{U} / \mathrm{ml}$ penicillin, and $0.1 \mathrm{mg} / \mathrm{ml}$ streptomycin (Gibco-BRL) at $37^{\circ} \mathrm{C}$ with $5 \% \mathrm{CO}_{2}$. For experiments testing aminoglycoside treatment, cells were plated to obtain approximately $70 \%$ confluence after $18 \mathrm{~h}$ of growth. For growth under cholesterol deficient conditions, cultures were grown in McCoy's 5A medium (Gibro-BRL) supplemented with $7.5 \%$ lipoprotein deficient serum (LPDS). ${ }^{22}$ Fibroblast cultures were treated with either G418 or gentamicin (Mediatech, Herndon, VA, USA) for $48 \mathrm{~h}$.

\section{Northern blot analysis}

A $5 \mu \mathrm{g}$ sample of total RNA was separated on a 1\% agarose/ formaldehyde gel and transferred to a Hybond-N+ nylon membrane (Amersham Pharmacia Biotech, Piscataway, NJ, USA). The DHCR7 probe was generated by RT-PCR with primers HSPl (5'-TCTAGATGGCGTCACCAATGAC-3') and HSP4 (5' -CTGTGAAATTGCAGTCTCTGG-3') using DHCR7 +/+ mRNA as template. ${ }^{4}$ The probe was labelled with ${ }^{32} \mathrm{P}$ using the Rediprime II Random Prime Labeling System (Amersham Pharmacia Biotech). A human GADPH probe was used to control for variation in RNA loading. Quantification of band intensity was performed using a BioImaging Analyzer (Fuji Medical Systems, Stomford, CT, USA).

\section{Fractional cholesterol synthesis}

To determine if DHCR7 enzymatic activity was increased by aminoglycoside treatment, human skin fibroblasts were cultured in McCoy's 5A Medium supplemented with 25\% deuterium oxide (Sigma, St Louis, MO, USA), 7.5\% LPDS, $100 \mathrm{U} / \mathrm{ml}$ penicillin, and $0.1 \mathrm{mg} / \mathrm{ml}$ streptomycin at $37^{\circ} \mathrm{C}$ with $5 \% \mathrm{CO}_{2}$. Incubation times and aminoglycoside concentrations are given in figure legends. Fractional cholesterol synthesis was determined by combined gas chromatography/flame ionisation detection and gas chromatography/mass spectrography for the analysis of deuterium labelled sterols. ${ }^{23}$

\section{RESULTS}

\section{Clinical descriptions and genotypes}

Patient 1

This phenotypically female infant was born at 38 weeks gestational age by caesarean section for breech presentation after an unremarkable pregnancy. There was poor respiratory effort and bag masked positive pressure ventilation followed by oxygen hood therapy was required. The clinical examination showed a head circumference of $32 \mathrm{~cm}$ (5th centile). Both weight and length were below the 5 th centile at $44 \mathrm{~cm}$ and $2200 \mathrm{~g}$, respectively. Craniofacial features included a small anterior fontanel, prominent occiput, wide nasal bridge, epicanthal folds, bilateral leukocoria, micrognathia, and cleft palate. Examination of the extremities was notable for a single palmar crease, clinodactyly, bilateral postaxial polydactyly of the hands, and bilateral 2-3 toe syndactyly. An echocardiogram revealed the presence of a partial AV canal defect with a small to moderate size primum atrial septal defect, mild mitral valve insufficiency, and a small patent ductus arteriosus. A renal ultrasound revealed the presence of small kidneys bilaterally. Although the infant appeared to have female genitalia, the karyotype was 46,XY. At 5 days of age, colonic aganglionosis was diagnosed, and at 9 days of age a brain MRI revealed a significant cerebellar hypoplasia with some degree of microgyria. The patient died at 22 days of age. Clinical severity score was 78 . The plasma sterols profile was cholesterol $0.11 \mathrm{mmol} / \mathrm{l}, 7 \mathrm{DHC} 0.29 \mathrm{mmol} / \mathrm{l}$, and 8-dehydrocholesterol (8DHC) $0.26 \mathrm{mmol} / \mathrm{l}$. DHCR7 genotype was IVS8- $1 \mathrm{G} \rightarrow \mathrm{C} / \mathrm{c} .452 \mathrm{G} \rightarrow \mathrm{A}(\mathrm{IVS} 8-\mathrm{lG} \rightarrow \mathrm{C} / \mathrm{Wl} 1 \mathrm{1X})$.

\section{Patient 2}

This phenotypically female infant was born at 36 weeks estimated gestational age to a 19 year old $\mathrm{G}_{1} \mathrm{P}_{0}$ Caucasian mother and a 16 year old Caucasian father. The mother was of Polish, English, and German heritage; the father's ethnic background was unknown. Prenatal ultrasound at 31 weeks revealed intrauterine growth retardation, limb anomalies, a large ventricular septal defect, and oligohydramnios. Amniocentesis was performed and the fetal karyotype was $46, \mathrm{XY}$. The infant was delivered by caesarean section due to fetal distress and breech presentation. The infant was intubated soon after birth for respiratory failure. Physical examination revealed the following: growth parameters in the 25th centile for gestational age (birth weight $2190 \mathrm{~g}$, length $43 \mathrm{~cm}$, head circumference $31.5 \mathrm{~cm}$ ), low-set ears, bilateral anterior polar cataracts, broad nasal bridge, anteverted nares, capillary haemangioma on the nose, micrognathia, cleft palate, broad alveolar ridges, shield-like chest, female external genitalia, and atretic anus. Limb anomalies consisted of bilateral upper extremity ectrodactyly, postaxial polydactyly of both feet, syndactyly of the second and third toes, and bilateral calcaneous valgus. Echocardiogram revealed a large, ventricular septal defect with an overriding aorta and right ventricular hypertrophy consistent with either a variant of tetralogy of Fallot or double outlet right ventricle. Head ultrasound was normal. Abdominal ultrasound revealed an atypical appearance of the left kidney without a definite focal mass. In addition, the abdominal ultrasound showed probable intra-abdominal testicles located near the inguinal canals with no evidence of female reproductive organs. Lower extremity radiographs revealed normal femora, tibiae, and fibulae but bilateral clubfoot abnormalities with hypoplastic hindfoot and phalanges. Upper extremity radiographs revealed normal humeri, symmetric mesomelic shortening of the forearms bilaterally with relatively greater shortening of the ulna, and lateral dislocation of the radial heads. Both hands were abnormal; only three metacarpals were identified in each hand, and three digits with relatively normal appearing phalanges were present on each hand. Cholesterol level was $0.16 \mathrm{mmol} / \mathrm{l}$ and the 7DHC level was $0.21 \mathrm{mmol} / \mathrm{l}$. Clinical severity score was 67 . The infant died on the 10th day of life. A postmortem examination was declined. DHCR7 genotype was c.452G $\rightarrow \mathrm{A} /$ c.461C $\rightarrow$ G (W151X/T154R).

\section{Patient 3}

This male infant was born to a 30 year old $\mathrm{G}_{5} \mathrm{P}_{3} \mathrm{SA}_{1}$ mother following an uncomplicated pregnancy and delivery; fetal movements were felt at 20 weeks of gestation and were of normal intensity. There were no prenatal tests and no significant family history. The infant was delivered at 39 weeks of gestation by spontaneous vaginal vertex delivery. Birth weight was $2940 \mathrm{~g}$ (25th centile), head circumference was $33 \mathrm{~cm}$ (10th centile), and length was $49 \mathrm{~cm}$ (25th centile). The infant had no difficulty feeding, but presented with dehydration and vomiting at 10 days of age because of pyloric stenosis and underwent pyloroplasty. Clinical 
diagnosis of SLOS was made at age 3 months. Karyotype was $46, \mathrm{XY}$. At 5 months of age plasma cholesterol was $1.24 \mathrm{mmol} / \mathrm{l}$, 7DHC was $0.06 \mathrm{mmol} / \mathrm{l}$, and $8 \mathrm{DHC}$ was $0.05 \mathrm{mmol} / \mathrm{l}$. At age 4.5 years, he was moderately mentally retarded. The child was able to walk in spite of the extreme tactile sensitivity of his feet. His speech consisted of only babbling. He was not toilet trained. He was restless and had opisthokinesis, but was generally happy and had no selfinjurious behaviour. His weight was $10.6 \mathrm{~kg}(-3.82 \mathrm{SD})$, height was $98 \mathrm{~cm}(-2 \mathrm{SD})$, and head circumference was $44 \mathrm{~cm}(-5.7 \mathrm{SD})$. He had unusual silvery blond hair. Facial features included bitemporal narrowing of the head with a prominent occiput and a prominent metopic suture, bilateral ptosis and epicanthal folds, high arched palate, thick irregular alveolar ridge, small tongue, and micrognathia. He had a haemangioma on the nasal tip. He had a micropenis with glandular epispadias and bilateral cryptorchidism. He had proximally set thumbs, overlapping fingers, ulnar deviation of the hands, and 2-3 toe syndactyly. He was Polish. Severity score was 30. DHCR7 genotype was c. $452 \mathrm{G} \rightarrow \mathrm{A} / \mathrm{c} .1054 \mathrm{C} \rightarrow \mathrm{T}(\mathrm{W} 151 \mathrm{X} / \mathrm{R} 352 \mathrm{~W})$.

\section{Patient 4}

This male patient was born to an 18 year old $\mathrm{G}_{2} \mathrm{P}_{1}$ mother who previously had a child who appeared to be affected with SLOS. This sibling died at 14 days of age with characteristic physical anomalies; however, the diagnosis was not confirmed by biochemical testing. The current pregnancy was not complicated; no prenatal testing was undertaken with the exception of sonographic evaluation at 28 weeks of gestation that detected multiple anomalies: ambiguous genitalia, short humeri, polydactyly of all extremities, and cerebral ventriculomegaly. The patient was born at 36 weeks of gestation by a spontaneous vaginal vertex delivery. His birth weight was $2600 \mathrm{~g}$ (50th centile), head circumference was $32 \mathrm{~cm}$ (25th centile), and length was $52 \mathrm{~cm}$ (90th centile). Cholesterol was $0.67 \mathrm{mmol} / \mathrm{l}, 7 \mathrm{DHC}$ was $0.22 \mathrm{mmol} /$ $\mathrm{l}$, and $8 \mathrm{DHC}$ was $0.29 \mathrm{mmol} / \mathrm{l}$. He had pneumonia at 1 month, recurrent otitis media, and chronic Salmonella diarrhoea. He had poor feeding requiring nasal gastric gavage feeding with recurrent vomiting. On examination at age 9.5 months his weight was $4.72 \mathrm{~kg}(-5.2 \mathrm{SD})$, length was $61.5 \mathrm{~cm}(-4.5 \mathrm{SD})$, and head circumference was $38.5 \mathrm{~cm}$ $(-6.33$ SD). Craniofacial features at 9.5 months included bitemporal narrowing, prominent occiput, high forehead, and a large open fontanel. He had bilateral ptosis and epicanthal folds, cleft palate, thick irregular alveolar ridge, bifid uvula, small tongue and micrognathia, and excessive sublingual tissue, as well as a long and flat philtrum. His neck was short and thick. He had an atrial septal defect, and there was a lowset left kidney. Genital anomalies consisted of a micropenis with penoscrotal hypospadias and bilateral cryptorchidism. Dysmorphic limb findings included rhizomelic shortening of all extremities, proximally set thumbs, overlapping fingers, bilateral single palmar creases, broad halluces, postaxial polydactyly of hands and feet, valgus deformities of the ankles, and Y shaped 2-3 toe syndactyly. He had agenesis of corpus callosum, generalised cortical atrophy, and was hypotonic. He was Polish. Clinical severity score was 60 . Karyotype was 46,XY. DHCR7 genotype was c.470T $\rightarrow$ C/ c. $452 \mathrm{G} \rightarrow \mathrm{A}(\mathrm{L} 157 \mathrm{P} / \mathrm{W} 151 \mathrm{X})$.

\section{Patient 5}

This patient was born at 40 weeks of gestation following an uncomplicated pregnancy to a primagravida woman by spontaneous vaginal vertex delivery. Birth weight was $2700 \mathrm{~g}$ (25th centile), head circumference was $31 \mathrm{~cm}(-3$ $\mathrm{SD})$, and length $49 \mathrm{~cm}$ (10th centile). Ambiguous genitalia were noted at delivery. He had a posterior fossa cyst noted on neonatal sonogram of the head. His infancy was marked by feeding difficulties and failure to thrive and recurrent ear infections and viral illnesses (measles, varicella, and rubella). On examination at age 4 years his weight was $9.1 \mathrm{~kg}(-4.5$ SD), height was $93.5 \mathrm{~cm}(-2.8 \mathrm{SD})$, and head circumference was $43.5 \mathrm{~cm} \quad(-5.9$ SD). Craniofacial features included bitemporal narrowing, prominent occiput, and high forehead with prominent metopic suture. His ears were large and floppy with prominent lobules and were low set. He had bilateral ptosis and epicanthal folds, a short and bulbous nose with anteverted nares, a high arched palate, a thick irregular alveolar ridge, and a small tongue. There was micrognathia and lateral hypoplasia of the midface. He had a short and thick neck. He had a micropenis with hypospadias and bilateral cryptorchidism with bifid scrotum and there was a sacral dimple. He had proximally set thumbs, short third digits, overlapping fingers, fifth finger clinodactyly, hypoplastic thumbs, and single palmar creases. He had complete 2-3 toe syndactyly and bilateral metatarsus adductus. At 4 years he had no speech and severe behavioural abnormalities (restlessness, tactile defensiveness, temper tantrums and aggression, head banging, self biting, and severe sleep disturbance). He had a history of severe photosensitivity. Clinical severity score was 20 . Cholesterol was $2.54 \mathrm{mmol} / \mathrm{l}$ and 7DHC was $0.38 \mathrm{mmol} / \mathrm{l}$ at age 2 years. He was Polish. Karyotype was $46, \mathrm{XY}$. DHCR7 genotype was c.452G $\rightarrow \mathrm{A} /$ c. $1054 \mathrm{C} \rightarrow \mathrm{T}(\mathrm{W} 151 \mathrm{X} / \mathrm{R} 352 \mathrm{~W})$.

\section{Patient 6}

This female child was born to a 33 year old $G_{3} S_{1} T_{1}$ mother following an uncomplicated pregnancy. Fetal movements were first perceived at 22 weeks, but were weak. She was delivered at 40 weeks of gestation by caesarean section because of maternal pneumothorax. Her birth weight was $3000 \mathrm{~g}$ (25th centile), length was $51 \mathrm{~cm}$ (50th centile), and head circumference was $32 \mathrm{~cm}$ (less than $3 \mathrm{rd}$ centile). This infant failed to thrive in the first year of life. Urethral narrowing was corrected surgically at age 14 months. Formal psychometric testing showed an IQ of 70. The child was described as always being very irritable. The diagnosis of SLOS was made clinically at 1.5 years of age and confirmed biochemically at age 6 . On physical examination at age 15 her weight was $37.7 \mathrm{~kg}(-2.0 \mathrm{SD})$, height was $152.3 \mathrm{~cm}$ (10th centile), and head circumference was $50.5 \mathrm{~cm}(-3.3 \mathrm{SD})$. Craniofacial features included bitemporal narrowing, prominent occiput and long midface with lateral hypoplasia. She had bilateral ptosis, minimal epicanthal folds, anteverted nares, high arched palate, and mild micrognathia. She had a sacral dimple and minimal 2-3 toe syndactyly. She was Polish. Clinical severity score was 20. At age 11 years cholesterol was $2.07 \mathrm{mmol} / \mathrm{l}, 7 \mathrm{DHC}$ was $0.06 \mathrm{mmol} / \mathrm{l}$, and $8 \mathrm{DHC}$ was $0.05 \mathrm{mmol} / \mathrm{l}$. Karyotype was 46,XX. DHCR7 genotype was c.452G $\rightarrow$ A/c.925G $\rightarrow$ A (W151X/G309S).

\section{Patient 7}

This male teenager was born to a 26 year old primagravida woman following a pregnancy complicated by a flu-like illness at 6-7 weeks of gestation. Fetal movements were felt at 6 months, but perceived as weak. He was delivered at 38 weeks by spontaneous vaginal vertex delivery with no neonatal complications. Birth weight was $2000 \mathrm{~g}$ (-3.4 SD), length was $49 \mathrm{~cm}$ (40th centile), and head circumference was $31 \mathrm{~cm}$ (3rd centile). He required gastrostomy tube feeding because of swallowing difficulties and a poor suck until 12 months of age. A clinical diagnosis of SLOS was made at age 7 years and confirmed biochemically at age 10 years with a cholesterol level of $3.16 \mathrm{mmol} / \mathrm{l}, 7 \mathrm{DCH}$ level of $0.13 \mathrm{mmol} / \mathrm{l}$, and $8 \mathrm{DHC}$ level of $0.09 \mathrm{mmol} / \mathrm{l}$. He had severe behavioural problems with restlessness, a high pitched cry, irritability, 
marked tactile defensiveness, and head banging. At the age of 11 years, he was severely developmentally delayed with no speech. On physical examination at age 14 years, he was wheelchair dependent. His weight was $27.3 \mathrm{~kg}(-2.5 \mathrm{SD})$, height was $144.5 \mathrm{~cm}(-2.13 \mathrm{SD})$, and his head circumference was $49 \mathrm{~cm}(-4.25 \mathrm{SD})$. He had very fair skin and unusual silver blond hair. He had lateral midface hypoplasia, shallow orbits, a high forehead, and his ears were very low set, posteriorly rotated and had prominent lobules. He had neither ptosis nor short palpebral fissures, but did have minimal epicanthal folds. He had a short nose with a bulbous nasal tip. His mouth was wide and the corners were down turned. He had micrognathia, irregularly spaced uneven teeth, and a high arched palate. He had a narrow thorax with wide set nipples, and his pelvis was narrow. Examination of the genitalia was notable for cryptorchidism, hypospadias, and micropenis. His second toes were curved over his third bilaterally, he had a proximally set thumb with ulnar deviation of all fingers, hyperextended fingers, and short second digits. He was unapproachable except for a very limited physical examination; he demonstrated severe tactile defensiveness of mouth, face, and extremities. Severity score was 30. He was Polish. Karyotype was 46,XY and DHCR7 genotype was c.452G $\rightarrow \mathrm{A} / \mathrm{c} .976 \mathrm{G} \rightarrow \mathrm{T}(\mathrm{W} 151 \mathrm{X} / \mathrm{V} 326 \mathrm{~L})$.

\section{Patient 8}

This young adult was born to a 32 year old primagravida mother after 42 weeks of gestation by spontaneous vaginal vertex delivery following an uncomplicated pregnancy. His birth weight was $3400 \mathrm{~g}$ (40th centile), length was $56 \mathrm{~cm}$ (25th centile), and head circumference was $34 \mathrm{~cm}$ (25th centile). He had feeding difficulties in spite of a good suck and required numerous hospitalisations for feeding issues. He underwent a hypospadias repair at age 12 years. He had no behavioural problems and his growth was appropriate. A clinical diagnosis of SLOS was made at age 7 months and confirmed biochemically at 15 years. Plasma cholesterol was $3.42 \mathrm{mmol} / \mathrm{l}, 7 \mathrm{DHC}$ was $0.60 \mathrm{mmol} / \mathrm{l}$, and $8 \mathrm{DHC}$ was $0.41 \mathrm{mmol} / \mathrm{l}$. At age 19.5 years, his weight was $61 \mathrm{~kg}$ (20th centile), height was $167.1 \mathrm{~cm}$ (below the 3rd centile), and head circumference was $56.6 \mathrm{~cm}$ (75th centile). He had bilateral short and proximally set thumbs and clinodactyly of second digits. Bilateral 2-3 toe syndactyly was present. He had a broad and high forehead with long midface; there was minimal lateral hypoplasia of the zygomas. Ears were prominent with simple helices and thick lobules. They were lop in appearance. He had micrognathia and a long philtrum. His nose was short and upturned. He had alternating esotropia. He was Polish. Severity score was 22. His karyotype was $46, \mathrm{XY}$ and his DHCR7 genotype was c.452C $\rightarrow \mathrm{A}$ / c. $808 \mathrm{~A} \rightarrow \mathrm{G}(\mathrm{W} 151 \mathrm{X} / \mathrm{M} 270 \mathrm{~V})$.

\section{Patient 9}

This male child was born to a 34 year old $\mathrm{G}_{2} \mathrm{P}_{1}$ mother. The mother smoked during pregnancy and had scarlet fever in the first trimester. Fetal movements were not perceived until the 6th month and were described as weak. Pregnancy was complicated by maternal hypertension and preeclampsia. The infant was delivered at 40 weeks of gestation by caesarean section because of breech presentation and maternal complications. His birth weight was $3850 \mathrm{~g}$ (75th centile), length was $58 \mathrm{~cm}$ (>97th centile), and head circumference was $36 \mathrm{~cm}$ (50th centile). He had hypoplastic genitalia and cryptorchidism. His newborn course was complicated by hypotonia and polycythemia. Feeding difficulties and vomiting necessitated gavage feeding. He had prolonged jaundice. The diagnosis of SLOS was made at 4 months of age. Plasma cholesterol was $1.24 \mathrm{mmol} / \mathrm{l}, 7 \mathrm{DHC}$ was $0.25 \mathrm{mmol} / \mathrm{l}$, and $8 \mathrm{DHC}$ was $0.19 \mathrm{mmol} / \mathrm{l}$. Fundoscopic examination, visual evoked potentials, and head and abdominal sonograms were all normal. On physical examination at age 3.1 years his weight was $11.25 \mathrm{~kg}(-2.5 \mathrm{SD})$, length was $92.3 \mathrm{~cm}(-0.9$ $\mathrm{SD})$, and head circumference was $46 \mathrm{~cm}$ (3rd centile). He had a high forehead, scaphocephaly with metopic ridging, and bitemporal narrowing. His palpebral fissures were down slanting with epicanthal folds and blepharophimosis. He had bilateral cataracts. His ears were moderately large and had large lobules. He had characteristic anteverted nares. He had a cleft palate, microglossia, abnormal tongue lobation, excess sublingual tissue, thick alveolar ridges, and micrognathia. His philtrum was long and he had lateral hypoplasia of the midface. His neck was short with excessive nuchal folds. He had an atrial septal defect. He had bilateral inguinal hernias and bifid scrotum. His hand digits had clinodactyly of the second and fifth fingers and there were very short and proximally set thumbs and abnormal palmar creases. He had partial 2-3 syndactyly with overlap of all toes. Clinical severity score was 40. He was Polish. His karyotype was 46,XY. DHCR7 genotype was c.452G $\rightarrow \mathrm{A} / \mathrm{c} .1054 \mathrm{C} \rightarrow \mathrm{T}(\mathrm{W} 151 \mathrm{X} / \mathrm{R} 352 \mathrm{~W})$.

\section{Patient 10}

This male patient was born to a 27 year old primagravida mother following a pregnancy complicated by placenta previa and cervical insufficiency treated with bed rest for 2 months. The infant was delivered at 36 weeks of gestation by spontaneous vaginal vertex delivery. His birth weight was $2500 \mathrm{~g}$ (25-30th centile) and length was $49 \mathrm{~cm}$ (75th centile). He was admitted to the NICU because of respiratory difficulties and he required ventilation. He had a cleft palate, patent ductus arteriosus and secundum atrial septal defect, and anal stenosis requiring a colostomy (biopsy was negative for colonic aganglionosis). He had hypertension of unknown etiology in the newborn period. He had severe feeding problems and required feeding supplementation with nasal gastric tube feeding. He underwent a patent ductus arteriosus ligation at 4 months of age. He had recurrent infections with pneumonia. Head sonogram showed bilateral grade IV intraventricular haemorrhages with hydrocephalus. He had incomplete bladder emptying on voiding cystourethrogram (VCUG). He was diagnosed with SLOS at 2 weeks of age. His plasma cholesterol was $0.73 \mathrm{mmol} / \mathrm{l}, 7 \mathrm{DHC}$ was $0.49 \mathrm{mmol} / \mathrm{l}$, and $8 \mathrm{DHC}$ was $0.18 \mathrm{mmol} / \mathrm{l}$. At age 3 years, his weight was $6.85 \mathrm{~kg}(-5.3 \mathrm{SD})$, length was $81 \mathrm{~cm}(-3.5 \mathrm{SD})$, and head circumference was $44 \mathrm{~cm}(-4 \mathrm{SD})$. He had very fair, unusual silver blond hair. There was a forehead haemangioma and severe photosensitivity. His forehead was narrow and high, he had shallow orbits with down slanting palpebral fissures, blepharophimosis, and epicanthal folds. He had a short bulbous nose with anteverted nares. He had a repaired cleft palate, micrognathia, microglossia with abnormal tongue lobation, excess sublingual tissue, and thick alveolar ridges. He had a long and deep philtrum. Limb anomalies included short thumbs, abnormal palmar creases, zigzag index fingers, ulnar deviation of the middle fingers, 2-3 toe syndactyly, rhizomelic shortening of the extremities, and valgus deformities of the ankles. Genital anomalies consisted of hypospadias, micropenis, bifid scrotum, and undescended testes. He had a history of severe tactile hypersensitivity of hands and feet and self-injurious behaviour and was aggressive. He had opisthokinesis and severely fragmented sleep. He was Polish. Severity score was 55. Karyotype was $46, \mathrm{XY}$ and DHCR7 genotype was $\mathrm{c} .452 \mathrm{G} \rightarrow \mathrm{A} / \mathrm{c} .976 \mathrm{G} \rightarrow \mathrm{T}$ (W151X/V326L).

\section{Patient 11}

The male child was the product of a 41 week gestation to a 32 year old $\mathrm{G}_{2} \mathrm{P}_{1}$ mother. Pregnancy was notable for decreased fetal activity. Birth weight was $3000 \mathrm{~g}$ (25th 


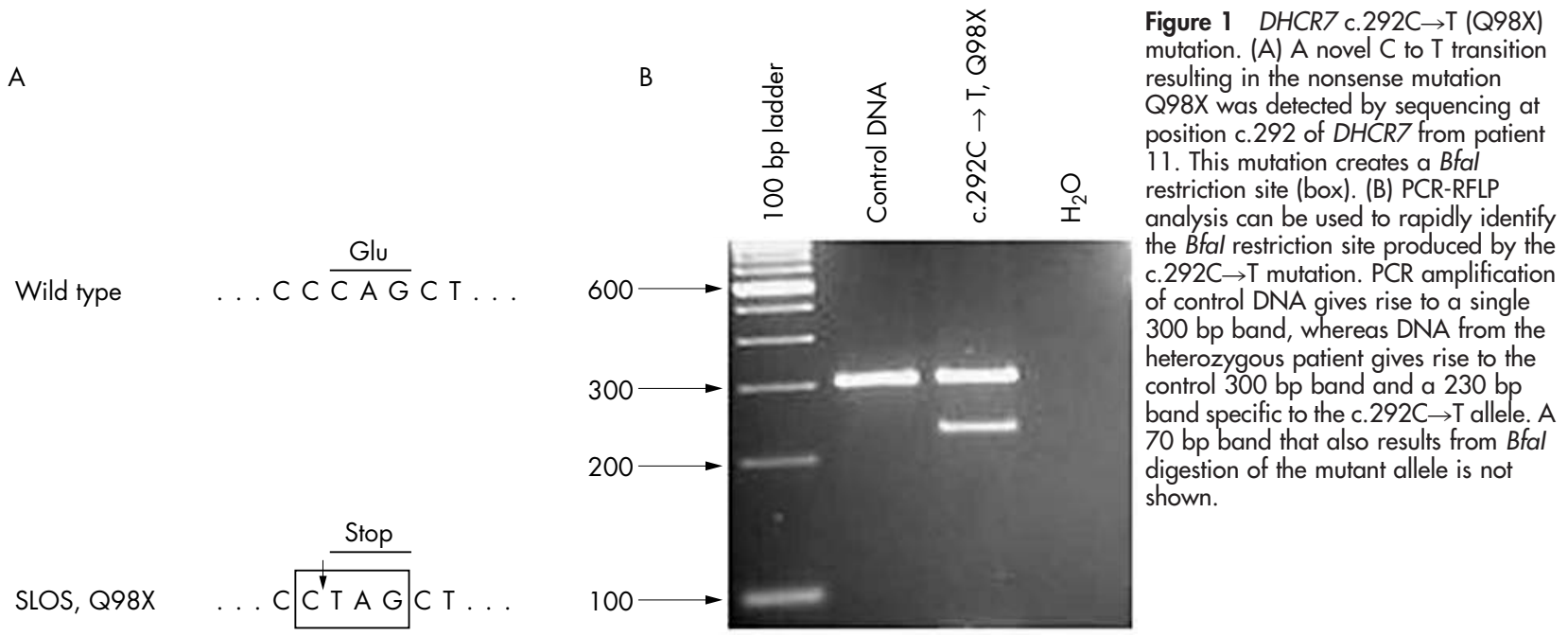

centile), length was $49 \mathrm{~cm}$ (25th centile), and head circumference was $33 \mathrm{~cm}$ (10th centile). The infant was noted to be hypotonic with calcaneovalgus deformity of the right foot. He was breast fed for the first 4 months, but was noted to have a poor suck. He had mild facial characteristics of SLOS, including microcephaly, frontal bossing, low-set ears, epicanthal folds, broad nasal bridge, short philtrum, and mild palatal hypertrophy. Bilateral 2-3 toe syndactyly was present. Growth was appropriate for the first 6 months of life but then fell to below the 5 th centile. Developmentally, the infant sat with support at 6 months of age, crawled at age 11 months, and walked at age 21 months. Behaviourally, he bites others and rarely plays with toys. A biochemical diagnosis of SLOS was made at 2 years of age. Both the mother and father are of Northern European ancestry. Clinical severity score was 6 . Plasma cholesterol was $2.95 \mathrm{mmol} / \mathrm{l}, 7 \mathrm{DHC}$ level was $0.14 \mathrm{mmol} / \mathrm{l}$, and $8 \mathrm{DHC}$ was $0.13 \mathrm{mmol} / \mathrm{l}$. DHCR7 genotype was c.292C $\rightarrow \mathrm{T} / \mathrm{c} .1349 \mathrm{G} \rightarrow \mathrm{T} \quad(\mathrm{Q} 98 \mathrm{X} / \mathrm{R} 450 \mathrm{~L}) . \quad$ The $\quad$ c.292C $\rightarrow \mathrm{T}$ mutation is a novel nonsense mutation which creates a $B f a I$ restriction site (fig 1). Sequencing of cDNA derived from mRNA demonstrated only a single c.1349G $\rightarrow$ T (R450L) mutation; however, genomic sequencing demonstrated a second mutation, c.292C $\rightarrow$ T (Q98X). We had previously observed similar results with cell lines that have a W151X allele. Thus, we postulated that both Q98X and W151X mRNA undergo NMD, and investigated the ability of aminoglycosides to suppress NMD and increase fractional cholesterol synthesis.

\section{Characterisation of NMD and aminoglycoside suppression of NMD for the Q98X and W151X mutations}

Suppression of NMD by aminoglycosides was studied in three SLOS fibroblast cell lines with premature stop codons $\mathrm{W} 151 \mathrm{X} / \mathrm{T} 93 \mathrm{M},{ }^{21} \mathrm{~W} 151 \mathrm{X} / \mathrm{IVS} 8-1 \mathrm{G} \rightarrow \mathrm{C}$ (patient 1), and Q98X/ R450L (patient 11). Sequencing of CDNA derived from fibroblasts treated with G418 demonstrated two alleles, whereas only one allele was observed in cDNA from untreated fibroblasts (fig 2). This effect was observed with both G4l8 (10-1000 $\mu \mathrm{g} / \mathrm{ml})$ and gentamicin $(10-500 \mu \mathrm{g} / \mathrm{ml}$, data not shown). Since RT-PCR amplification of cDNA was not quantitative, we used northern blot analysis to evaluate DHCR7 expression in IVS8-1G $\rightarrow$ C/W151X fibroblasts treated with $0,10,25$, or $50 \mu \mathrm{g} / \mathrm{ml}$ of G418 (fig 3A). DHCR7 expression increased almost twofold between untreated and treated cells $(0.047 v 0.081,0.098$, and 0.107 photo stimulated luminescent units $/ \mathrm{mm}^{2}$ for $0 v 10,25$, and $50 \mu \mathrm{g} / \mathrm{ml}$ of G418, respectively). A significant increase in expression was not detected in IVS8-1G $\rightarrow$ C/W151X fibroblasts treated with gentamicin, and a quantifiable increase in expression of DHCR7 mRNA was not detected in Q98X/R450L fibroblasts treated with G418 (data not shown). This later result is likely due to significant background expression of the R450L allele in the cell line from this mildly affected patient.

Because G418 suppresses NMD of both the W151X and Q98X alleles, we investigated whether DHCR7 enzymatic activity could be increased by treatment with G418. Fractional cholesterol synthesis was measured in IVS8$\mathrm{IG} \rightarrow \mathrm{C} / \mathrm{IVS} 8-\mathrm{lG} \rightarrow \mathrm{C}, \mathrm{IVS8}-\mathrm{IG} \rightarrow \mathrm{C} / \mathrm{Wl} 1 \mathrm{IX}$, and Q98X/R450L cell lines treated with $0,10,25$, or $50 \mu \mathrm{g} / \mathrm{ml}$ of $\mathrm{G} 418$. The IVS8- $\mathrm{GG} \rightarrow \mathrm{C}$ allele is a null allele, thus an increase in

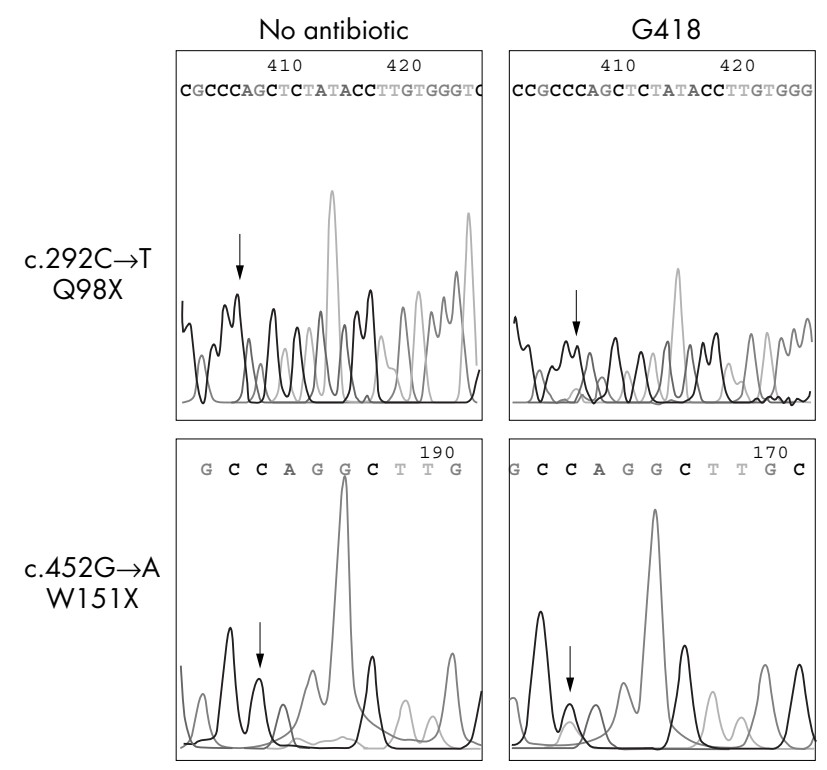

Figure 2 Q98X and W151X transcripts undergo NMD. RNA was isolated from untreated (left panels) or G418 treated (right panels) skin fibroblasts. For both the Q98X (top panels) and W151X (bottom panels) cell lines, sequencing of RT-PCR products derived from untreated cells appeared to be homozygous for the wild type sequence (arrows). However, after treatment with G418, sequencing of RT-PCR products showed that these cell lines were heterozygous for the Q98X and W151X mutant alleles (arrows). These data demonstrate that RNA transcripts from these two mutant alleles undergo NMD and that NMD can be suppressed by G418 treatment. Note that the antisense sequence is shown for the W151X allele. 
fractional cholesterol synthesis in the IVS8-1G $\rightarrow$ C/W151X cell line could be attributed to the W15IX allele. Under these culture conditions, significant toxicity was observed in cultures treated with 25 and $50 \mu \mathrm{g} / \mathrm{ml}$ of G418. At $10 \mu \mathrm{g} / \mathrm{ml}$ of G418 we were not able to detect deuterium labelled (newly synthesised) cholesterol in either IVS8-1G $\rightarrow$ C/IVS8- IG $\rightarrow$ C (data not shown) or IVS8-1G $\rightarrow$ C/W151X (fig 3B) cell lines. Experimental conditions were used under which we are able to detect $12.95 \mathrm{pmol}$ of cholesterol-D6 diluted into $518 \mathrm{pmol}$ of cholesterol. For the Q98X/R450 cell line, significant residual activity is present in untreated cells due to the R450L allele; however, we were able to detect a significant increase (SD) in fractional cholesterol synthesis from 0.28 $(0.02)$ to $0.37(0.04)(\mathrm{p}<0.01)$ when these cells were treated with $10 \mu \mathrm{g} / \mathrm{ml}$ of G418 (fig 3B).

\section{Phenotypic severity and genotype}

Establishing a genotype-phenotype correlation for SLOS has been confounded by the large number of mutant alleles and

A

DHCR7 genotype

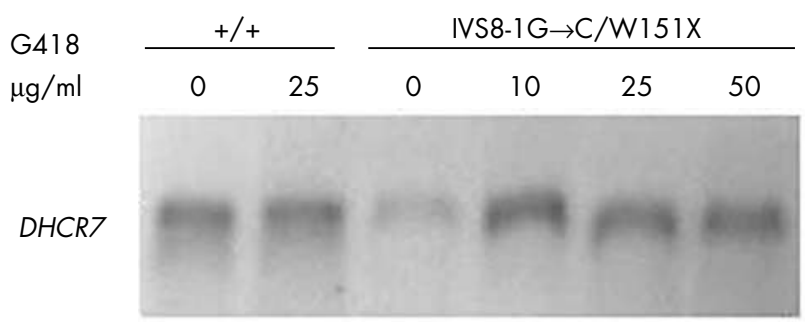

GADPH

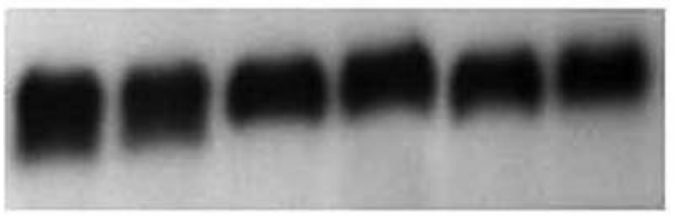

B

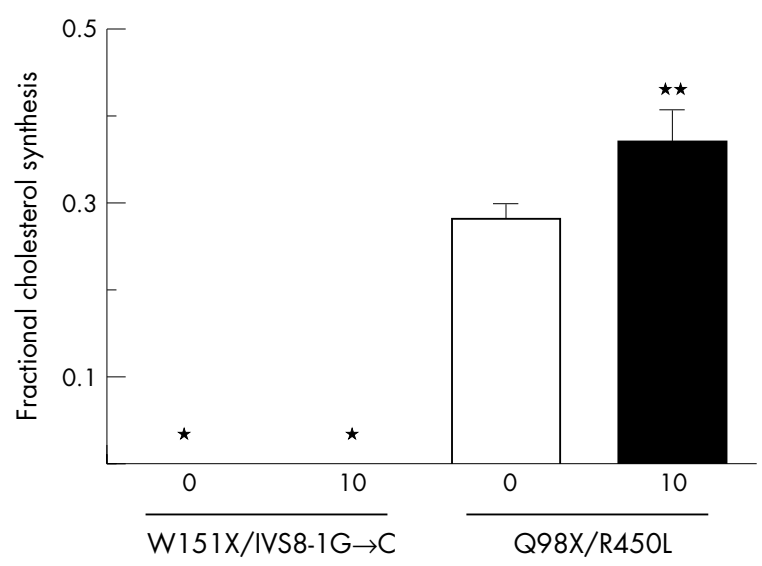

G418 $(\mu \mathrm{g} / \mathrm{ml})$

Figure 3 Suppression of Q98X and W151X NMD by G418. (A) Northern blot analysis of DHCR7 expression in control (+/+) and IVS8$1 \mathrm{G} \rightarrow \mathrm{C} / \mathrm{W} 151 \mathrm{X}$ skin fibroblasts treated with the indicated dose of G418. DHCR7 expression increased in the IVS8-1G $\rightarrow$ C/W151X cell line in response to treatment with G418. The same membrane was probed using a GAPDH probe to establish equivalent RNA loading. (B) Fractional cholesterol synthesis is significantly increased in the Q98X/ R450L cell line after treatment with $10 \mu \mathrm{g} / \mathrm{ml}$ of G418. *Fractional cholesterol synthesis was below our limit of detection for both the untreated and treated W151X/IVS8-1G $\rightarrow$ C cultures. ${ }^{* *} \mathrm{p}<0.01$. the fact that most patients are compound heterozygotes. The W151X allele, like the more common splice acceptor mutation, IVS8-1G $\rightarrow$ C, is a null allele. Thus, one would predict that phenotypic variability due to DHCR7 genotype would be related to the second allele, and because of this, clinical characterisation of patients with W151X alleles is of interest. Figure 4 presents the genotype and clinical severity of a series of patients with the more common DHCR7 mutant alleles found in association with either IVS8-1G $\rightarrow C$ or W151X. This figure is a compilation of data of the W151X patients presented above, unpublished data, and previously reported cases. ${ }^{23-32}$ As expected, IVS8-1G $\rightarrow$ C and W151X homozygous as well as W151X/IVS8-1G $\rightarrow$ C patients are severely affected. There were only two patients with this genotype who had severity scores less than 50. One IVS8$\mathrm{IG} \rightarrow \mathrm{C} / \mathrm{IVS}-\mathrm{IG} \rightarrow \mathrm{C}$ patient with a clinical severity score of 30 died at 30 days of life, ${ }^{29}$ and another infant with a severity score of 45 was severely affected with alobar holoprosencephaly, ambiguous genitalia, polydactyly, and respiratory distress, and died at 8 days of age. Although most patients with a T93M/null (IVS8-1G $\rightarrow$ C or W151X) genotype have a mild to classical phenotypic presentation, as previously reported, ${ }^{24}$ a distinct subset of patients has a more severe presentation $(\mathrm{p}<0.001)$. Clinical severity scores for patients with V326L/null and R404C/null genotypes range from classical to severe. In contrast, clinical severity for the R352W/null genotype ranges from mild to classical. Except for the lack of W151X/R404C patients, no significant differences between the WI51X and IVS8-1G $\rightarrow$ C alleles were observed.

\section{DISCUSSION}

SLOS is a multiple malformation/mental retardation syndrome due to an inborn error of cholesterol biosynthesis. Unlike many human malformation syndromes but similar to inborn errors of metabolism, postnatal correction of the underlying biochemical defect may have beneficial therapeutic effects. Currently, dietary cholesterol supplementation is being used in attempts to treat individuals with SLOS $^{12}$; however, efficacy is limited by a number of factors including inability of dietary cholesterol to cross the blood-brain barrier.

Establishing a genotype-phenotype correlation for SLOS has been confounded by the fact that over 90 different DHCR7 mutations have been identified, and most patients are compound heterozygotes. In this manuscript, we have presented the phenotypic description of 10 patients with the W15IX allele and a single patient with a novel Q98X allele. Because nonsense alleles, like the common IVS8$\mathrm{IG} \rightarrow \mathrm{C}$ allele, are null alleles, description of these patients is important since any observed genotype-phenotype correlations would be due to the second allele. Figure 4 presents the correlation between clinical severity and a series of mutant alleles found in association with either an IVS8-1G $\rightarrow$ C or W151X allele. Although this information will be of general use in genetic counselling, this series expands and confirms our previous observation that other factors in addition to genotype significantly influence clinical severity scores. ${ }^{24}$ These factors could involve maternal factors or other genes involved in cholesterol synthesis/homeostasis or cholesterol metabolism to steroids or oxysterols. Recently, WitschBaumgartner et $a l^{33}$ have reported that maternal apoE genotype is significantly correlated with phenotypic severity.

Although limb malformations are typical of SLOS, ectrodactyly is not commonly observed. Ectrodactyly has been reported previously in three cases of $\operatorname{SLOS}^{34-36}$; however, patient 2 is the first SLOS patient for whom the diagnosis was both biochemically and molecularly confirmed.

Since the W151X allele is found in approximately $6.4 \%$ of SLOS patients, suppression of NMD is a potential therapeutic approach that could be considered in this subset of SLOS 


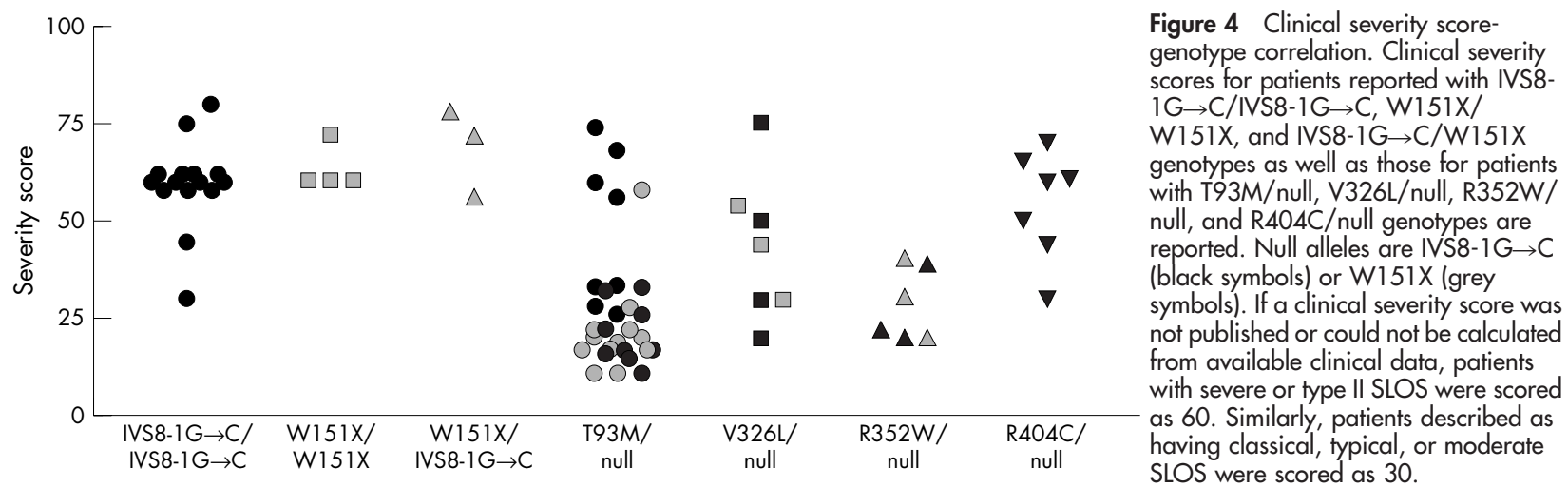

patients. In this manuscript, we demonstrate that both the common DHCR7 $7^{\mathrm{W} 151 \mathrm{x}}$ and the newly identified DHCR7 $7^{\mathrm{Q} 98 \mathrm{X}}$ alleles undergo NMD. Although aminoglycoside antibiotics are unlikely to be used therapeutically, they serve as a model system to demonstrate that suppression of NMD may have therapeutic benefit. Future development of less toxic drugs that suppress NMD would be of value in the treatment of many genetic disorders. We thus tested the ability of aminoglycoside antibiotics to suppress NMD in SLOS fibroblasts. We were able to demonstrate a significant increase of fractional cholesterol synthesis in the Q98X/ R450L fibroblast line treated with $10 \mu \mathrm{g} / \mathrm{ml}$ of G418. The high basal level of DHCR7 activity in this cell line is presumably due to the R450L allele that has residual enzymatic function. Given the allele frequency, we were most interested in determining if increased DHCR7 activity could be demonstrated for the W151X allele. For these experiments we used an IVS8-1G $\rightarrow$ C/W151X fibroblast line since the IVS8-1G $\rightarrow$ C allele is a null allele. Although NMD of the W151X allele could be suppressed, we were unable to detect any significant increase in fractional cholesterol synthesis in the IVS8$1 \mathrm{G} \rightarrow \mathrm{C} / \mathrm{W} 15 \mathrm{IX}$ cell line treated with $10 \mu \mathrm{g} / \mathrm{ml}$ of $\mathrm{G} 418$. For the determination of fractional cholesterol synthesis, use of higher G418 concentrations was precluded by toxicity. Thus, although NMD of the W151X transcript can be suppressed, active DHCR7 protein does not appear to be produced. This suggests that the W151 amino acid of DHCR7 is a critical residue that cannot be substituted. Little structural data is available for DHCR7. However, W151 is predicted to be in a transmembrane domain by several models. ${ }^{3}{ }^{1637}$ Numerous other mutations have been reported in this predicted transmembrane domain. Thus, our conclusion that W15l encodes a critical residue is consistent with the idea that this region of the protein is critical for enzymatic function.

\section{DISCLAIMER}

The opinions or assertions contained herein are the private views of the authors (NRD and SWL) and are not to be construed as official or as reflecting the views of the Department of the Army, Department of the Navy, or the Department of Defense.

\section{ACKNOWLEDGEMENTS}

We would like to thank the parents and patients for their willingness to participate in this research study.

\section{Authors' affiliations}

L S Correa-Cerro, C A Wassif, P A Krakowiak, D Cozma, F D Porter, Unit on Molecular Dysmorphology, Heritable Disorders Branch, National Institute of Child Health and Human Development, National Institutes of Health, Department of Health and Human Services, Bethesda, MD, USA
J S Waye, M J M Nowaczyk, Department of Pathology and Molecular Medicine and Pediatrics, McMaster University, Hamilton, ON, Canada N R Dobson, Department of Pediatrics, National Naval Medical Center, Bethesda, MD, USA

S W Levin, Department of Pediatrics, Walter Reed Army Medical Center, Washington, DC, USA

G Anadiotis, Legacy Children's Hospital, Pediatric Development and Rehabilitation, Portland, OR, USA

R D Steiner, Departments of Pediatrics and Molecular and Medical Genetics, Child Development Rehabilitation Center, Doernbecher Children's Hospital, Oregon Health \& Science University, Portland, OR, USA

M Krajewska-Walasek, Department of Medical Genetics, The Children's Memorial Health Institute, Warsaw, Poland

LCC is supported by a Fogarty Center Fellowship at the National Institutes of Health.

Competing interests: none declared

${ }^{*}$ Current address: University of Arkansas for Medical Sciences, Little Rock, AR, USA.

Correspondence to: Forbes D Porter, Heritable Disorders Branch, NICHD, NIH, DHHS, Bld. 10, Rm. 9S241, 10 Center Dr., Bethesda, MD 20892, USA; fdporter@mail.nih.gov

Received 12 May 2004

Revised version received 16 June 2004

\section{REFERENCES}

1 Kelley RI, Hennekam RC. The Smith-Lemli-Opitz syndrome. J Med Genet 2000;37(5):321-35.

2 Porter FD. Human malformation syndromes due to inborn errors of cholesterol synthesis. Curr Opin Pediatr 2003;15(6):607-13

3 Fitzky BU, Witsch-Baumgartner M, Erdel M, Lee JN, Paik YK, Glossmann H, Utermann G, Moebius FF. Mutations in the Delta7-sterol reductase gene in patients with the Smith-Lemli-Opitz syndrome. Proc Natl Acad Sci U S A 1998.95(14):8181-6.

4 Wassif CA, Maslen C, Kachilele-Linjewile S, Lin D, Linck LM, Connor WE, Steiner RD, Porter FD. Mutations in the human sterol delta7-reductase gene at 11 q12-13 cause Smith-Lemli-Opitz syndrome. Am J Hum Genet 1998;63(1):55-62.

5 Waterham HR, Wijburg FA, Hennekam RCM, Vreken P, Poll-The BT, Dorland L, Duran M, Jira PE, Smeitink JAM, Wevers RA, Wanders RJA. SmithLemli-Opitz syndrome is caused by mutations in the 7-dehydrocholesterol reductase gene. Am J Hum Genet 1998;63:329-38.

6 Battaile KP, Battaile BC, Merkens LS, Maslen CL, Steiner RD. Carrier frequency of the common mutation IVS8-1G >C in DHCR7 and estimate of the expected incidence of Smith-Lemli-Opitz syndrome. Mol Genet Metab 2001;72(1):67-71.

7 Nowaczyk MJ, Nakamura LM, Eng B, Porter FD, Waye JS. Frequency and ethnic distribution of the common DHCR7 mutation in Smith-Lemli-Opitz syndrome. Am J Med Genet 2001;102(4):383-6.

8 Cooper MK, Wassif CA, Krakowiak PA, Taipale J, Gong R, Kelley RI, Porter FD, Beachy PA. A defective response to Hedgehog signaling in disorders of cholesterol biosynthesis. Nat Genet 2003;33(4):508-13.

9 Frischmeyer PA, Dietz HC. Nonsense-mediated mRNA decay in health and disease. Hum Mol Genet 1999;8(10):1893-900.

10 Howard M, Frizzell RA, Bedwell DM. Aminoglycoside antibiotics restore CFTR function by overcoming premature stop mutations. Nat Med 1996;2(4):467-9.

11 Clancy JP, Bebok Z, Ruiz F, King C, Jones J, Walker L, Greer H, Hong J, Wing L, Macaluso M, Lyrene R, Sorscher EJ, Bedwell DM. Evidence that 
systemic gentamicin suppresses premature stop mutations in patients with cystic fibrosis. Am J Respir Crit Care Med 2001;163(7):1683-92.

12 Wilschanski M, Yahav Y, Yaacov Y, Blau H, Bentur L, Rivlin J, Aviram M, Bdolah-Abram T, Bebok Z, Shushi L, Kerem B, Kerem E. Gentamicin-induced correction of CFTR function in patients with cystic fibrosis and CFTR stop mutations. N Engl J Med 2003;349(15):1433-41.

13 Keeling KM, Brooks DA, Hopwood JJ, Li P, Thompson JN, Bedwell DM. Gentamicin-mediated suppression of Hurler syndrome stop mutations restores a low level of alpha-L-iduronidase activity and reduces lysosomal glycosaminoglycan accumulation. Hum Mol Genet 2001; 10(3):291-9.

14 Keeling KM, Bedwell DM. Clinically relevant aminoglycosides can suppress disease-associated premature stop mutations in the IDUA and P53 cDNAs in a mammalian translation system. J Mol Med 2002;80(6):367-76.

15 Yu H, Lee MH, Starck L, Elias ER, Irons M, Salen G, Patel SB, Tint GS. Spectrum of delta(7)-dehydrocholesterol reductase mutations in patients with the Smith-Lemli-Opitz (RSH) syndrome. Hum Mol Genet 2000;9(9):1385-91.

16 Waterham HR, Wanders RJ. Biochemical and genetic aspects of 7 dehydrocholesterol reductase and Smith-Lemli-Opitz syndrome. Biochim Biophys Acta 2000;1529(1-3):340-56.

17 Jira PE, Waterham HR, Wanders RJ, Smeitink JA, Sengers RC, Wevers RA. Smith-Lemli-Opitz syndrome and the DHCR7 gene. Ann Hum Genet 2003;67(pt 3):269-80.

18 Witsch-Baumgartner M, Ciara E, Loffler J, Menzel HJ, Seedorf U, Burn J, Gillessen-Kaesbach G, Hoffmann GF, Fitzky BU, Mundy H, Clayton P, Kelley RI, Krajewska-Walasek M, Utermann G. Frequency gradients of DHCR7 mutations in patients with Smith-Lemli-Opitz syndrome in Europe: evidence for different origins of common mutations. Eur J Hum Genet $2001 ; 9(1): 45-50$.

19 Kelley RI. Diagnosis of Smith-Lemli-Opitz syndrome by gas chromatography/ mass spectrometry of 7-dehydrocholesterol in plasma, amniotic fluid and cultured skin fibroblasts. Clin Chim Acta 1995;236(1):45-58.

20 Wright BS, Nwokoro NA, Wassif CA, Porter FD, Waye JS, Eng B, Nowaczyk MJ. Carrier frequency of the RSH/Smith-Lemli-Opitz IVS8-1G >C mutation in African Americans. Am J Med Genet 2003;120A(1):139-41.

21 Krakowiak PA, Nwokoro NA, Wassif CA, Battaile KP, Nowaczyk M, Connor WE, Maslen C, Steiner RD, Porter FD. Mutation analysis and description of sixteen RSH/Smith-Lemli-Opitz syndrome patients: polymerase chain reaction-based assays to simplify genotyping. Am J Med Genet 2000;94(3):214-27

22 Cham BE, Knowles BR. A solvent system for delipidation of plasma or serum without protein precipitation. J Lipid Res 1976;17:176-81.

23 Wassif CA, Krakowiak PA, Wright BS, Correa-Cerro LS, Sterner AL, Javitt NB, Yergey AL, Porter FD. Fractional cholesterol synthesis and simvastatin induction of cholesterol synthesis in Smith-Lemli-Opitz syndrome (submitted for publication).
24 Porter FD. RSH/Smith-Lemli-Opitz syndrome: a multiple congenital anomaly/ mental retardation syndrome due to an inborn error of cholesterol biosynthesis. Mol Genet Metab 2000;71(1-2):163-74

25 Nowaczyk MJ, Martin-Garcia D, Aquino-Perna A, Rodriguez-Vazquez M, McCaughey D, Eng B, Nakamura LM, Waye JS. Founder effect for the T93M DHCR7 mutation in Smith-Lemli-Opitz syndrome. Am J Med Genet 2004; 125A(2):173-6.

26 Witsch-Baumgartner M, Fitzky BU, Ogorelkova M, Kraft HG, Moebius FF, Glossmann H, Seedorf U, Gillessen-Kaesbach G, Hoffmann GF, Clayton P, Kelley RI, Utermann $\mathrm{G}$. Mutational spectrum in the delta7-sterol reductase gene and genotype-phenotype correlation in 84 patients with Smith-LemliOpitz syndrome. Am J Hum Genet 2000;66(2):402-12.

27 Patrono C, Dionisi-Vici C, Giannotti A, Bembi B, Digilio MC, Rizzo C, Purificato C, Martini C, Pierini R, Santorelli FM. Two novel mutations of the human delta7-sterol reductase (DHCR7) gene in children with Smith-LemliOpitz syndrome. Mol Cell Probes 2002;16(4):315-8.

28 Jira PE, Wanders RJ, Smeitink JA, De Jong J, Wevers RA, Oostheim W, Tuerlings JH, Hennekam RC, Sengers RC, Waterham HR. Novel mutations in the 7-dehydrocholesterol reductase gene of 13 patients with Smith-LemliOpitz syndrome. Ann Hum Genet 2001;65(pt 3):229-36.

29 Goldenberg A, Chevy F, Bernard C, Wolf C, Cormier-Daire V. [Clinical characteristics and diagnosis of Smith-Lemli-Opitz syndrome and tentative phenotype-genotype correlation: report of 45 cases]. Arch Pediatr 2003;10(1): 4-10 (in French).

30 Loeffler J, Utermann G, Witsch-Baumgartner M. Molecular prenatal diagnosis of Smith-Lemli-Opitz syndrome is reliable and efficient. Prenat Diagn 2002;22(9):827-30

31 Nowaczyk MJ, Eng B, Waye JS, Farrell SA, Sirkin WL. Fetus with renal agenesis and Smith-Lemli-Opitz syndrome. Am J Med Genet 2003;120A(2):305-7.

32 Nowaczyk MJ, Farrell SA, Sirkin WL, Velsher L, Krakowiak PA, Waye JS, Porter FD. Smith-Lemli-Opitz (RHS) syndrome: holoprosencephaly and homozygous IVS8-1G $\rightarrow$ C genotype. Am J Med Genet 2001;103(1):75-80.

33 Witsch-Baumgartner M, Gruber M, Kraft HG, Rossi M, Clayton P, Giros M Haas D, Kelley RI, Krajewska-Walasek M, Utermann G. Maternal apo E genotype is a modifier of the Smith-Lemli-Opitz syndrome. J Med Genet 2004; 41 (8):577-84

34 Singer LP, Marion RW, Li JK. Limb deficiency in an infant with Smith-LemliOpitz syndrome. Am J Med Genet 1989;32(3):380-3.

35 Worthington S, Goldblatt J. Smith-Lemli-Opitz syndrome: further delineation of the phenotype. Clin Dysmorphol 1997;6(3):263-6.

36 de Jong G, Kirby PA, Muller LM. RSH (Smith-Lemli-Opitz) syndrome: "severe" phenotype with ectrodactyly. Am J Med Genet 1998;75(3):283-7.

37 Jang JC, Fujioka S, Tasaka M, Seto H, Takatsuto S, Ishii A, Aida M, Yoshida S, Sheen J. A critical role of sterols in embryonic patterning and meristem programming revealed by the fackel mutants of Arabidopsis thaliana. Genes Dev 2000;14(12):1485-97. 